\title{
Gewebt, gewirkt, geflochten
}

Liebe Leserin, lieber Leser,

uch heute wird der Begriff "Textil“ der Tradition
folgend zuerst mit Produkten aus der Bekleidungs-
branche assoziiert. Doch in technischer Hinsicht haben die Stoffe eine fast ebenso lange Geschichte, wobei die der See- oder Ballonfahrt wohl am imposantesten ist. Im neuzeitlicheren Gebrauch sind Textilien in nahezu allen Lebensbereichen unverzichtbar. Kaum ins öffentliche Bewusstsein vorgedrungen, leisten zum Beispiel Geotextilien seit Jahren einen verlässlichen Beitrag, wenn es darum geht, Hangrutsche zu vermeiden oder Deponien abzusichern. Die Leistungsfähigkeit eines Reifens wird erst durch die Karkasse möglich, und der kunststoffbasierte Leichtbau erreicht mit Geweben, Gelegen, Geflechten oder Gewirken aus unterschiedlichen Fasern erst seine hohe Festigkeit.

Welche Möglichkeiten Textilien im Automobilbau bieten, zeigt der Beitrag der TU Dresden in dieser ersten Ausgabe von Iwd im neuen Jahr. Die Kombination mehrerer Funktionen in einem Bauteil ermöglicht es zum Beispiel, Leichtbau und passive Fahrzeugsicherheit zu vereinen. Mit einer sandwichartigen Motorhaubenkonstruktion, bei der eine Dämmlage aus Textil zwischen unterschiedlichen Decklagen positioniert ist, lassen sich Gewicht einsparen und die Dämpfung zum Beispiel beim Kopfaufprall steigern. Ferner skizziert
Dr. Klaus Jansen vom Forschungskuratorium Textil in Berlin in seinem Übersichtsbeitrag Aspekte des großen Themengebiets Leichtbau. Er beschreibt auch die Forschungsrichtung der kommenden Jahre und zeigt, wie sich völlig neue Anwendungsgebiete textilverstärkter Werkstoffe entwickeln. Besonders Bau- und Medizinbereich haben dabei offenbar ein großes Potenzial.

Forschung und Entwicklung bei technischen Textilien sind ein weites Feld. Allein die Faser- und Garntechnologie bietet zahlreiche Ansätze, Neues herauszufinden. Um Flächenstrukturen zu konfektionieren, also gebrauchsfähig zu gestalten und für ihr jeweiliges Einsatzgebiet zu funktionalisieren, bedarf es ebenfalls weiterer Studien, was vor allem die Maschinentechnik einschließt. Anwendungsgebiete gibt es genug, und es scheint, als ob noch nicht alle entdeckt sind.

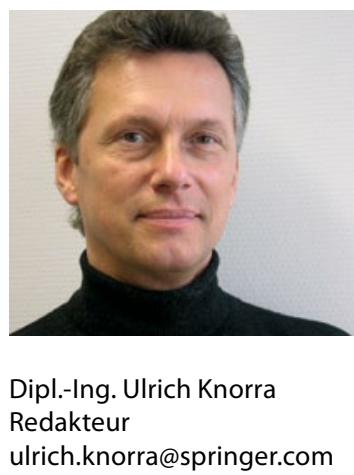

